\title{
Optimal bridge to recovery strategy for children
}

\section{Teruhiko Imamura}

Second Department of Internal Medicine, University of Toyama, Toyama, Japan

Correspondence to: Teruhiko Imamura, MD, PhD, FAHA, FACC, FESC, FHFSA, FAPSC, FACP, FICA, FJCC. Second Department of Internal Medicine, University of Toyama, 2630 Sugitani, Toyama 930-0194, Japan. Email: teimamu@med.u-toyama.ac.jp.

Submitted Mar 27, 2021. Accepted for publication Jun 20, 2021.

doi: $10.21037 / \mathrm{cdt}-21-188$

View this article at: https://dx.doi.org/10.21037/cdt-21-188

Optimal strategy of bridge to recovery using ventricular assist device in children with advanced heart failure remains unestablished. Javier Delmo and colleagues demonstrated that post-weaning myocardial recovery and cardiac stability of children with advanced heart failure receiving ventricular assist device was feasible when the weaning was appropriately performed according to their institutional protocol (1). Several concerns have been raised.

The authors stated that they administered standard heart failure medications following the implantation of ventricular assist device (1), but data were not presented. Detailed data including doses of each medication and discussion regarding the implication of up-titration of these medications targeting bridge to recovery should be valuable to understand optimal bridge to recovery strategy.

In addition to the weaning test that the authors proposed, any procedures to assess patients' cardiac reserve, including iodine-123 meta-iodobenzylguanidine scintigraphy (2), might be useful to predict the probability of cardiac reverse remodeling.

In their study, the post-weaning freedom from heart failure recurrence was $96 \%$ during a mean followup duration of 9.0 years and none of the weaned patients underwent repeat ventricular assist device implantation (1). Given such a favorable clinical outcome following the device explantation, now might be a time to expand the indication of device explantation and modify the weaning protocol.

\section{Acknowledgments}

Funding: TI receives grant support from JSPS KAKENHI: JP20K17143.

\section{Footnote}

Provenance and Peer Review: This article was a standard submission to the journal. The article was sent for external peer review.

Conflicts of Interest: The author has completed the ICMJE uniform disclosure form (available at: http://dx.doi. org/10.21037/cdt-21-188). The author receives grant support from JSPS KAKENHI: JP20K17143, and has no other conflicts of interest to declare.

Ethical Statement: The author is accountable for all aspects of the work in ensuring that questions related to the accuracy or integrity of any part of the work are appropriately investigated and resolved.

Open Access Statement: This is an Open Access article distributed in accordance with the Creative Commons Attribution-NonCommercial-NoDerivs 4.0 International License (CC BY-NC-ND 4.0), which permits the noncommercial replication and distribution of the article with the strict proviso that no changes or edits are made and the original work is properly cited (including links to both the formal publication through the relevant DOI and the license). See: https://creativecommons.org/ licenses/by-nc-nd/4.0/.

\section{References}

1. Javier Delmo EM, Javier MFDM, Böthig D, et al. Heart failure in the young: Insights into myocardial recovery with ventricular assist device support. Cardiovasc Diagn Ther 2021;11:148-63. 
2. Imamura T, Kinugawa K, Nitta D, et al. Preoperative iodine-123 meta-iodobenzylguanidine imaging is a novel predictor of left ventricular reverse remodeling during

Cite this article as: Imamura T. Optimal bridge to recovery strategy for children. Cardiovasc Diagn Ther 2021;11(4):10201021. doi: $10.21037 / \mathrm{cdt}-21-188$ treatment with a left ventricular assist device. J Artif Organs 2016;19:29-36. 